\title{
Estimating DSGE model parameters in a small open economy: Do real-time data matter ${ }^{1}$ \\ Jan Čapek ${ }^{2}$
}

\begin{abstract}
This paper investigates the differences between parameters estimated using real-time and those estimated with revised data. The models used are New Keynesian DSGE models of the Czech, Polish, Hungarian, Swiss, and Swedish small open economies in interaction with the euro area. The paper also offers an analysis of data revisions of GDP growth and inflation and trend revisions of interest rates.

Data revisions are found to be unbiased and not autocorrelated in all countries. Inflation is usually measured more accurately in real-time than GDP growth, but this is not the case in the euro area. The results of the core analysis suggest that there are significant differences between parameter estimates using real-time data and those estimated using revised data. The model parameters that are most prone to significant differences between real-time and revised estimations are habit in consumption and persistence of domestic supply, of demand, and of world-wide technology shocks. The impulse response analysis suggests that the model behavior based on real-time and revised data is different.
\end{abstract}

Key words: real-time data, revision, DSGE model, Bayesian estimation, recursive estimation

JEL Classification: C11, C55, C82, F41

\section{Introduction}

The typical procedure for using data in DSGE models is to download ready-to-use time series from databases like Eurostat or OECD, compute the required data transformations and use these as observable variables. However, this procedure has potential drawbacks if the data used are subject to revision, which is typically the case for frequently used series like GDP or inflation. Time series of data that are subject to revision mix together revised and unrevised data: the latest observation is typically a first (or even flash) esti-

\footnotetext{
${ }^{1}$ I am grateful to three anonymous referees for their helpful comments and suggestions. Computational resources were provided by the MetaCentrum under the program LM2010005 and the CERIT-SC under the program Centre CERIT Scientific Cloud, part of the Operational Program Research and Development for Innovations, Reg. no. CZ.1.05/3.2.00/08.0144.

A companion paper investigates the differences between the parameter estimates pertaining to monetary policy using real-time data, and those using revised data. See Čapek (2014).

${ }^{2}$ Department of Economics, Faculty of Economics and Administration, Masaryk University, Brno, capek@econ.muni.cz
} 
mate of the current value, while observations that are several years old have often already undergone many revisions. ${ }^{3}$ The aim of this paper is to identify possible differences between models estimated using only revised data and models estimated with data from databases that mix revised and unrevised data.

Theoretically, most DSGE model parameters are more precisely estimated with the revised data, although policy parameters, for example, are more precisely estimated using the real-time data that were available to the policymaker at the time of decisionmaking. Policy parameters reflect the policymaker's reaction to data that are observed in real-time. Using revised data for historical analysis of policy parameters may result in misleading conclusions. ${ }^{4}$ On the other hand, AR1 parameters and arguably also structural parameters are more precisely estimated using revised data.

This paper sets out to address the outlined issues concerning data revisions in several ways. Firstly, it offers an analysis of data revisions. Secondly, it estimates parameters using real-time and revised data and compares the results; it therefore provides some indication of the influence of using real-time data for model results. Thirdly, it offers a brief analysis of model behavior with impulse response functions analysis in order to find out whether the model behavior estimated with real-time data and final data differs.

This study uses a small-scale open economy macroeconomic DSGE model to analyze the importance of real-time data in small open Czech, Polish, Hungarian, Swiss, and Swedish economies, respectively, in interaction with the big closed euro area economy. The analysis proceeds from a Bayesian estimation of model parameters, and its results are also presented in terms of the statistical significance of the differences in parameter estimates.

\section{Literature Review}

The unreliability of real-time macroeconomic data is a well-known issue, and many studies have investigated the properties of data revisions. Orphanides and van Norden (2002) report that the main issue is not revision of published U.S. data; it is the unreliability of end-of-sample trend estimates. On the other hand, Cusinato et al. (2013) show that data revision and the end-of-sample problem both contribute to uncertainty about the Brazilian output gap, but do not find any evidence that the former is less important than the latter. Investigating the empirical properties of U.S. macroeconomic data, Aruoba (2008) finds out that revisions to the data are biased and predictable. Rusnák (2013) reports that revisions of Czech GDP data and its components are rather large. He also studies whether these revisions are "news" or "noise", i.e. whether the revisions are predictable or unpredictable. The investigation ascertains in-sample predictability and out-of-sample unpredictability for most variables of interest.

\footnotetext{
${ }^{3}$ Galvão (2013) calls this issue the apples-oranges-mixing problem and analyzes it using a DSGE model in a forecasting exercise.

${ }^{4}$ See e.g. Orphanides (2001) and other papers mentioned in the literature review.
} 
A great deal of research effort has also been focused on exploring the analytic consequences of using real-time data in analysis. One stream of literature concentrates on monetary policy: e.g. Orphanides (2001) uses a Taylor-type rule as an example of different policy recommendations based on real-time vs. final data, and argues that a monetary policy reaction function estimated on final data provides a misleading description of historical policy. Similar conclusions, i.e. that real-time data play a (significant) role were reached by Aurelio (2005), Gerdesmeier and Roffia (2005), Gerberding et al. (2005), Horváth (2009), and Belke and Klose (2011). More recent literature also uses DSGE models with monetary rules as a tool for monetary policy investigation. Vázquez et al. (2010) and Casares and Vázquez (2012) establish that monetary policy parameters are robust to real-time specification. On the other hand, Neri and Ropele (2012) show that there is indeed a statistically significant difference in policy parameters when realtime data are considered.

Kolasa et al (2012) put a New-Keynesian DSGE model to the test in real-time forecasting with data from the Survey of Professional Forecasters (SPF). The paper concludes that if we support the model with SPF nowcasts, the model forecasts reasonably well.

Clements and Galvão (2011) concentrate on business cycle analysis and establish that using also older data vintages improves output gap and inflation trend estimates in real time.

This paper also features an analysis in the spirit of Croushore and Stark (2003), where authors show that using different data vintages may lead to (statistically significantly) different estimates of model parameters.

Interested readers may turn to Croushore (2011) for an extensive survey of real-time data literature.

\section{Methodology and Preliminaries}

\subsection{Model}

This paper uses a New Keynesian (NK) Dynamic Stochastic General Equilibrium (DSGE) model. The model is derived from microeconomic behavior of particular economic agents. These include domestic and foreign households, domestic and foreign producers, domestic importers and domestic and foreign monetary authorities. Most of the model assumptions are adopted from Lubik and Schorfheide (2006). ${ }^{5}$

The model is in a small open economy (SOE) setting, so it presumes two countries - a small open economy influenced by a big closed economy. Also, the model incorporates the exchange rate channel, and the two countries in the model should therefore have different currencies. Finally, the formulation of the interest rate rule corresponds best with an inflation targeting regime.

\footnotetext{
${ }^{5}$ See the online Appendix to the companion paper, Čapek (2014), for details.
} 
Given the typical scope of the journal, this study concentrates on the Visegrád Four countries, of which three meet the restrictions given by the model formulation. ${ }^{6}$ In addition, the Swiss and Swedish economies are also modelled, as these can serve as a useful comparison to the V4 countries. The small open economies are therefore the Czech, Hungarian, Polish, Swedish, and Swiss economies, respectively. In all cases, the euro area (incorporating 12 countries) is the big large economy.

\subsection{Data}

The observed variables were chosen in accordance with Lubik and Schorfheide (2006), where the authors use quarterly data for seven observable variables - output growth, CPI inflation and 3-month nominal interest rate for domestic and foreign economies, and the growth rate of bilateral nominal exchange rate.

The data were acquired from OECD databases. GDP and Consumer Price Index were acquired from a real-time database ${ }^{7}$, whilst the interest rates and the exchange rates were acquired from Key Economic Indicators ${ }^{8}$.

Real-time data is usually structured in vintages. A "vintage" is a quarter when the data become available, or, the time of publishing. For example, if Czech Statistical Office releases an estimate of GDP growth for the last quarter of 2012 sometime in April of 2013, it is said that the data for the fourth quarter of 2012 are in the vintage of April of 2013.

The term "real-time" data addresses data that become available right after collection. Real-time macroeconomic data are usually available 3-4 months after the end of a quarter, typically being the first estimates published for that quarter. As time passes, new vintages become available and revised data become more accurate estimates of real values. The most recent vintage is referred to as the "final" value. The difference between the final and real-time data is a "total revision".

The original OECD real-time dataset for CPI has 180 monthly vintages (February 1999 - January 2014) that cover from 36 (January 1996 - December 1998) to 215 monthly observations (January 1996 - November 2013). The original real-time dataset for GDP also has 180 monthly vintages that cover from 11 (1996Q1 - 1998Q3) to 71 quarterly observations (1996Q1 - 2013Q3). ${ }^{9}$

\footnotetext{
${ }^{6}$ Slovakia does not have independent monetary policy.

${ }^{7}$ http://stats.oecd.org/mei/default.asp?rev=1

${ }^{8} \mathrm{http}: / /$ stats.oecd.org/Index.aspx?DataSetCode=KEI. Note that Hungarian interest rate has several missing observations in OECD database. The series was substituted from Eurostat database (the data are virtually the same) where there is only one missing observation in 2004q3 which was linearly interpolated.

${ }^{9}$ Missing observations occur at some vintages for some countries. Such vintages are not used for the estimation.
} 
GDP in constant prices that is not seasonally adjusted in the dataset was seasonally adjusted in Demetra ${ }^{10}$ program by Tramo\&Seats method. Computed growth rates are log-differences, quarter-on-quarter. Monthly Consumer Price Index was also seasonally adjusted. The third month in each quarter was used to compute quarter-on-quarter inflation (as log-differences). Both dataset were truncated so that there are at least 30 quarterly observations for the estimation.

Finally, there is an issue of which monthly vintages to select for estimation in each quarter. Since the model is quarterly, there are three choices available: to use January/April/July/October vintages, February/May/August/November vintages, or March/June/September/December vintages. There are many difficulties with this choice and arguably, none of the options is ideal. The approach used in this article is to use the vintage set that ensures the highest number of balanced real-time data subsets. A balanced real-time data subset in this context means that it includes the same number of quarterly observations for both GDP growth and inflation. This approach is convenient in that we do not need to discard any existing quarterly observations, nor do we need to estimate (nowcast) any non-existent observations. However, there are also drawbacks to this approach. Firstly, since we focus only on quarterly observations, we disregard any monthly observations of inflation that may be available. Secondly, this approach does not discriminate between flash estimates (of GDP) and "regular" releases of national accounts data ${ }^{11}$. Thirdly, the unbalanced real-time data subsets are not addressed - the affected vintages are simply not used for the estimation, and no results are reported for that vintage.

There are no real-time datasets for the remaining observable variables, and truncated time series are therefore used for the estimation. The interest rates are 3-month interbank rates without any transformation. ${ }^{12}$ Quarterly nominal exchange rates were collected as "USD monthly averages" and transformed into domestic currency vs. euro in direct quotation, which means that its increase in value reflects the depreciation of the domestic currency. ${ }^{13}$ The growth rate of the nominal exchange rate was calculated as log-differences.

If originally published data need to be detrended prior to use, the issue of trend recomputation comes into play as well. When new data become available, the influence can be seen in two directions. Firstly, the new vintage delivers more accurate data for historical periods - this influence is often referred to as "data revision". Secondly, new data points

\footnotetext{
${ }^{10} \mathrm{http} / / /$ circa.europa.eu/irc/dsis/eurosam/info/data/demetra.htm

${ }^{11}$ I've conducted a sensitivity analysis (on Czech data and baseline setting) and used all three possible choices of sets of monthly vintages (in this case, ragged ends were cut) and the similarity of the results do not suggest there is a problem of vintages choice.

${ }^{12}$ Note that several missing values were filled in with Eurostat data which are consistent with OECD's data.

${ }^{13}$ This selection and computation was used because OECD dataset does not contain currencies quoted in EUR. The calculations were cross-checked against datasets of Eurostat, and the series are virtually the same.
} 
for the new period enable a more accurate estimation of the trend for historical periods this influence is "trend revision". The sum of data and trend revisions yields total revision.

Table 1 summarizes which macroeconomic variables are subject to data revision, and which are subject to trend revision. Domestic and foreign GDP growth and inflation are part of the real-time database, and are therefore subject to data revision. However, these variables are stationary, and detrending only requires deducting the means. ${ }^{14}$ Trend revision in the case of a constant trend is negligible, which is the reason why it is omitted in this study. Interest rates are not subject to data revisions, but are not stationary. The interest rates in the euro area are detrended by a (linear) time trend. Domestic interest rates are even more irregular and are detrended by a Hodrick-Prescott filter with $\lambda=1600$. Nominal exchange rate growth is not subject to data revision and the series is stationary, which means that this series is not subject to any revision. Due to the availability of variables in the real-time database and the choice of detrending methods, no variable is subject to both revisions.

Table 1 Data, Trend, and Total Revision

\begin{tabular}{llll} 
Variable & Data revision & Trend & Total revision \\
\hline domestic GDP growth & yes & constant & $=$ data revision \\
domestic inflation & yes & constant & $=$ data revision \\
domestic interest rate & no & HP filter $=$ trend revision \\
foreign GDP growth & yes & constant $=$ data revision \\
foreign inflation & yes & constant $=$ data revision \\
foreign interest rate & no & linear & $=$ trend revision \\
nom. exchange rate growth & no & constant $=$ none
\end{tabular}

Notes: Domestic economies are various small open economies. Foreign economy is the euro area.

In order to conveniently distinguish between data and trend revisions, the concept of socalled "quasi real-time" data is usually introduced. ${ }^{15}$ Quasi real-time data are constructed knowing the latest vintage but not knowing future values. The researcher knows what data revision for today's value will occur tomorrow but she does not know any values for tomorrow's time period. Therefore, quasi real-time data only isolates trend revision. This implies that quasi real-time data minus real-time data is data revision, and final data minus quasi real-time data is trend revision.

\footnotetext{
${ }^{14}$ As a robustness check, I re-estimated the baseline model of Polish small open economy with the inflation gap used in the Taylor rule that is constructed as a difference of inflation and inflation target. In most parameters, the results for inflation gap specification and de-meaned specification differ only insignificantly. For a few parameters, there is a level shift, but the dynamics is again very similar.

${ }^{15}$ See e.g. Orphanides and van Norden (2002) and Ince and Papell (2013).
} 
All observable variables enter the model as quarter-on-quarter growth rates (interest rates are quarterly) and per quartal. ${ }^{16}$

\subsection{Recursive Estimates and Statistical Significance}

This study undertakes a recursive analysis in order to analyze the influence of the use of real-time data on the differences model parameter estimates in the course of time. The recursive analysis is conducted in a way that the first observation is always the same, and the last observation shifts by a quarter each time a new estimation is carried out. A logical implication is that the time frame of the estimate grows. The series of such estimates may be intuitively perceived as the exploration of the information in the newlyadded data. Although this intuition is not entirely correct, this paper concentrates on the influence of real-time data rather than on weaknesses of recursive estimation.

The log-linearized DSGE model is estimated by Bayesian methods. A numericaloptimization procedure is used to maximize the posterior. At least 1,000,000 draws from posterior density are generated with a random-walk Metropolis-Hastings algorithm after which the convergence is checked according to Gelman and Rubin (1992) convergence diagnostics. If the chain does not converge, 1,000,000 more samples are added, and the convergence is rechecked until convergence is reached. ${ }^{17,18}$ Then, $90 \%$ of the original sample is discarded and the rest is used for posterior analysis. The estimation is carried out in Dynare software ${ }^{19}$. Monte-Carlo based optimization routine is used for computing the mode so that different estimates all reach suitable acceptation rate. $\mathrm{Pa}$ rameters' prior densities are the same for all estimates.

Note that data enter the estimation in respective vintages for each estimation. The data source for one "real-time" macroeconomic variable is therefore not one time series, but a matrix of data with separate vintages. Although computationally more demanding, this approach mimics more tightly the data actually available to economic agents in any point in time.

For real-time estimates, the trend estimates are based only on the data that were actually available. For quasi real-time estimates, all data are fully revised but values for future periods are not known. For final estimates, all data are fully revised and future values are available for the computation of the trend. In order to capture the evolution of the estimates, final data series are truncated to match the period of estimation.

\footnotetext{
${ }^{16}$ See part 3.5 for two exceptions with selective year-on-year transformation.

${ }^{17}$ When the chain does not converge, results are not reported.

${ }^{18}$ The convergence is considered successful when $R$ statistic (Gelman and Rubin 1992, p. 465) for all parameters is 1.03 or lower. As the potential scale reduction is given by $\sqrt{R}$, the required value of the potential scale reduction factor is 1.0149 . Note that „When the potential scale reduction is near 1 , we conclude that each set of the $m$ sets of $n$ simulated values is close to the target distribution." (Gelman and Rubin 1992, p. 465)

${ }^{19}$ See http://www.dynare.org/; version 4.4.1 was used.
} 
In order to be able to conclude whether potential differences between real-time, quasi real-time and final estimates are statistically significant, section 4 reports the lowest significance level at which the (major) mode is out of Highest Posterior Density bands for the two most different estimates.

\subsection{Estimated Variants}

The study offers several different model specifications, data treatments and estimation procedures to show the robustness of the results. The setting introduced in sections 3.1 and in the Appendix is called baseline.

CPI not s.a. stands for model variant with Consumer Price Index not seasonally adjusted, GDP HP denotes a variant with growth rate of Gross Domestic Product detrended by Hodrick-Prescott filter, rolling uses estimation (of baseline model) in a moving window of fixed length $30, Y O Y$ stands for a variant with monetary authorities that care for year-on-year (rather than quarter-on-quarter) changes and $Y O Y+G D P H P$ denotes a variant with monetary authorities that care for year-on-year changes and GDP is detrended by HP filter.

\section{Recursive Analysis of Real-Time Data}

Figure 1 displays both real-time and final data for small open economies and the euro area economy. Note that in order for the magnitude and regularity of data revisions to be visible, the data are not detrended here. Also, in order to form one "real-time" time series for each macroeconomic variable, only the most recent data point per vintage is considered. This treatment corresponds to the use of "real-time" data in literature and is therefore directly comparable. ${ }^{20}$ However, note that the estimation does not use the depicted series, but separate vintages.

Figure 1 Real-time and Final Data

CZ GDP growth, mean $=2.17, \mathrm{MAE}=1.33$ p.p.

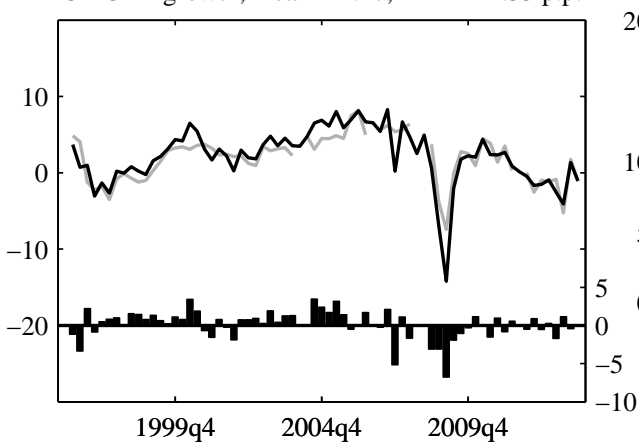

$\mathrm{CZ}$ inflation, mean $=3.33, \mathrm{MAE}=0.55$ p.p.

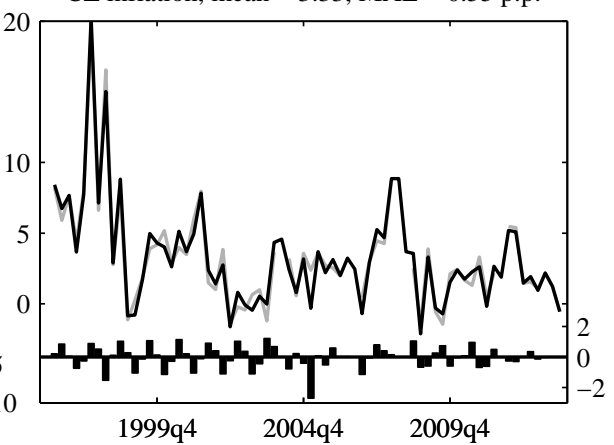

${ }^{20}$ Orphanides (2001), Rusnák (2013), and Belke and Klose (2011) among many others. 


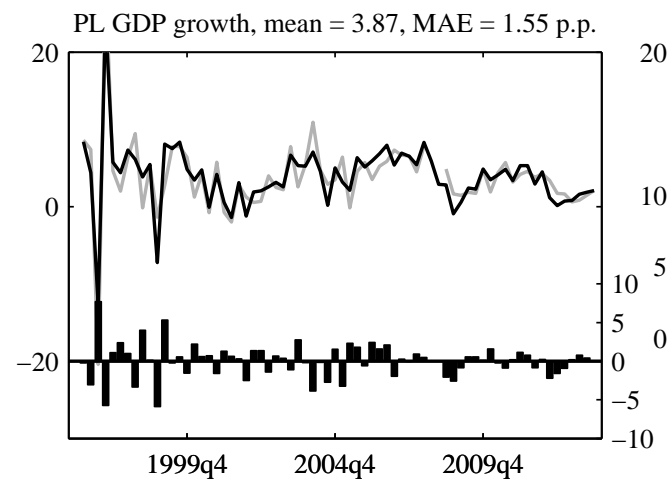

PL inflation, mean $=4.74$, MAE $=0.64$ p.p.
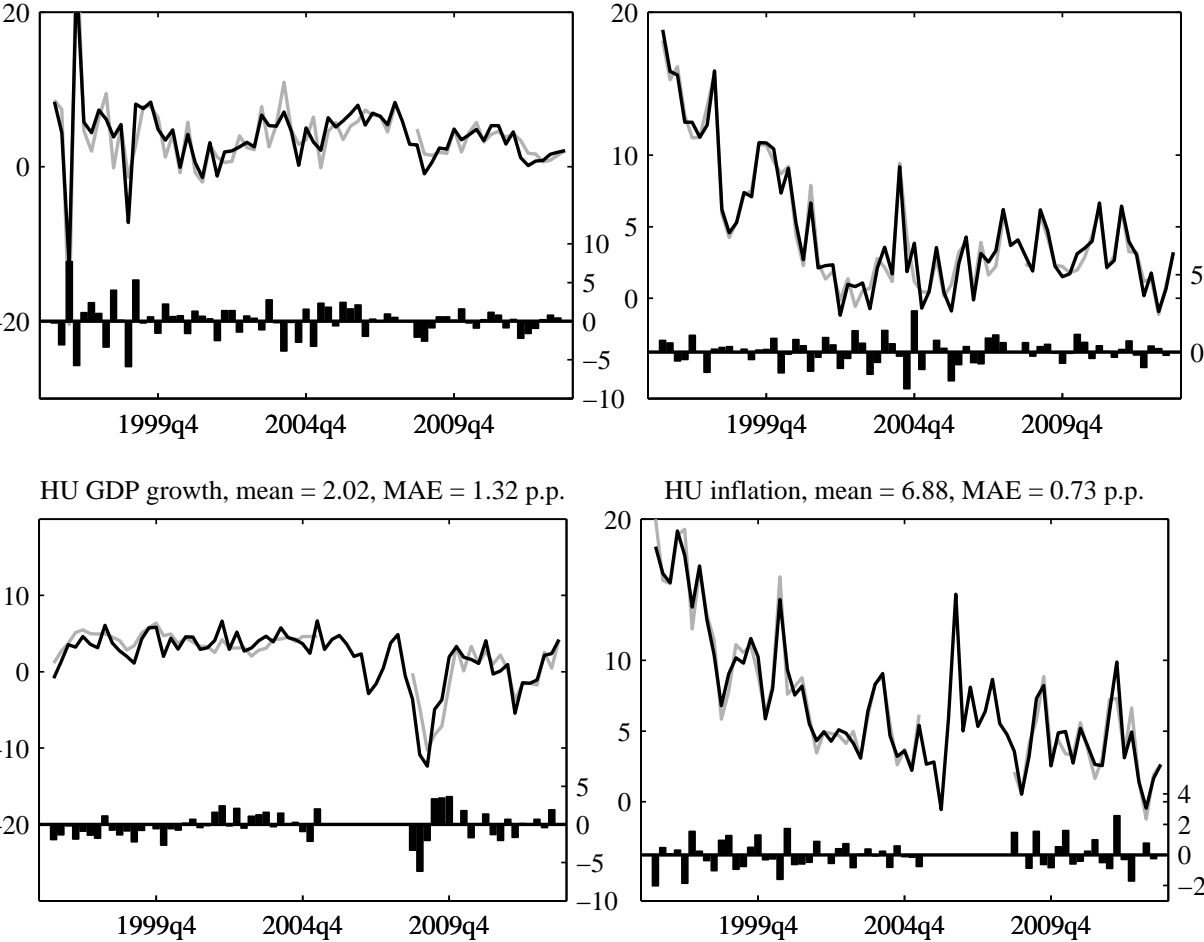

$\mathrm{HU}$ inflation, mean $=6.88, \mathrm{MAE}=0.73$ p.p.

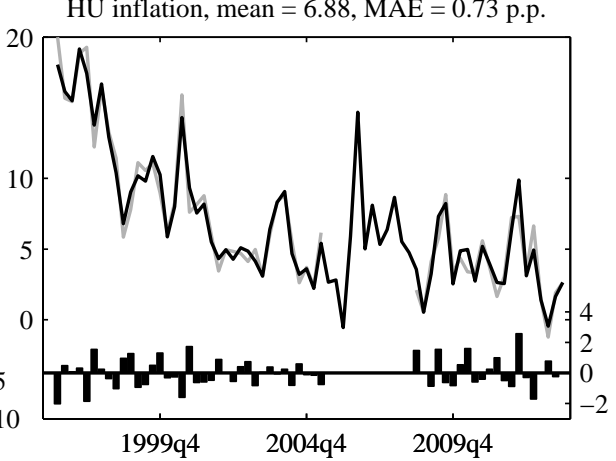

$\mathrm{CH}$ GDP growth, mean $=1.81, \mathrm{MAE}=1.08$ p.p.

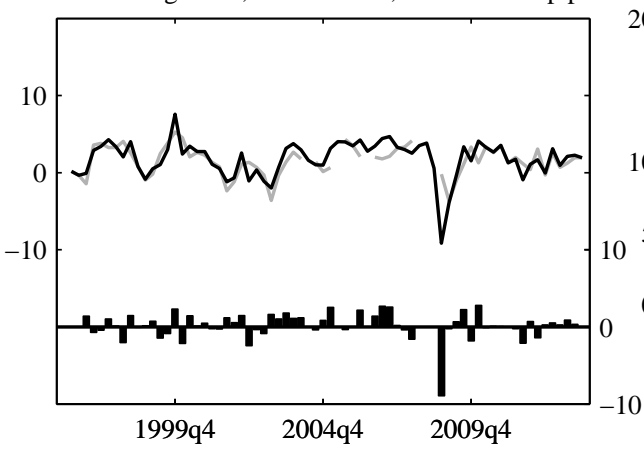

$\mathrm{CH}$ inflation, mean $=0.63, \mathrm{MAE}=0.46$ p.p.

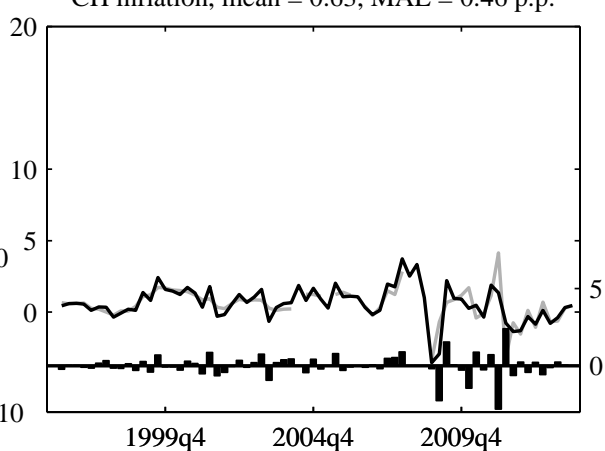



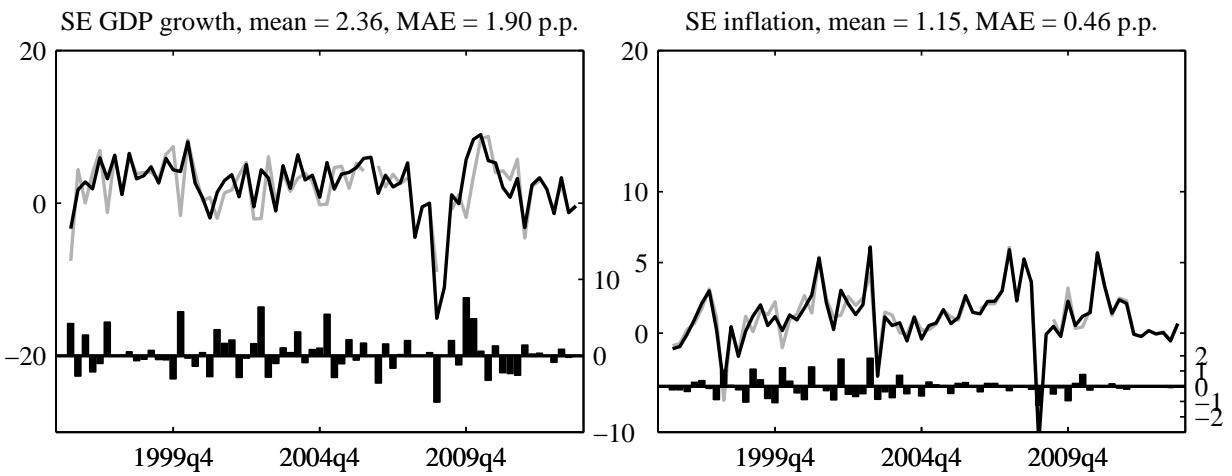

EA GDP growth, mean $=1.41$, MAE $=0.58$ p.p.

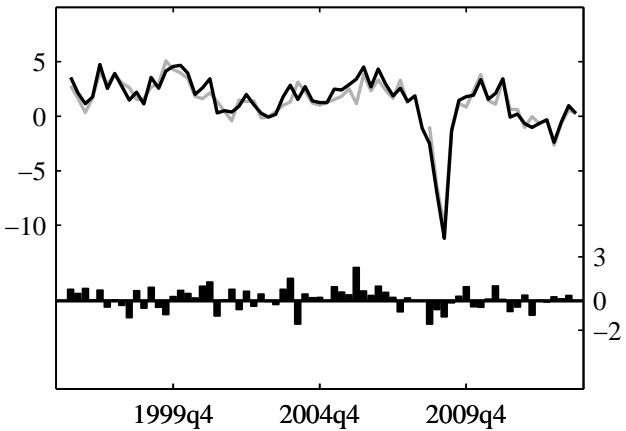

EA inflation, mean $=1.94, \mathrm{MAE}=0.30$ p.p.

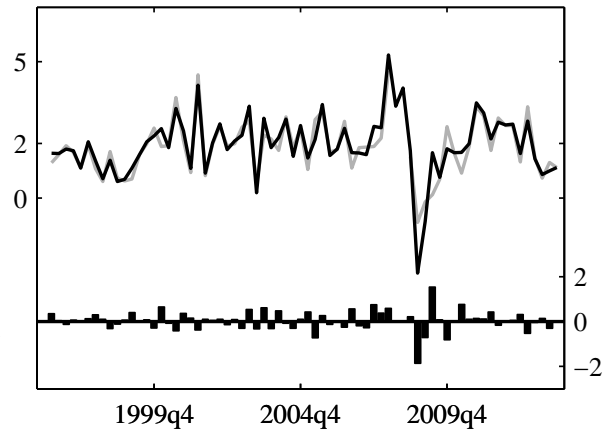

Notes: the black line denotes final data (left axis), the grey line denotes real-time data (left axis), the error bar depicts data revision (right axis), the mean denotes the average of final data over the sample, and MAE denotes mean absolute error in data revision. $C Z=C$ zech Republic, $P L=$ Poland, $\mathrm{HU}=$ Hungary, $\mathrm{CH}=$ Switzerland, $\mathrm{SE}=$ Sweden, $E A=$ Euro area (12 countries $)$.

In absolute terms, GDP growth suffers from revision more than inflation in all countries shown (see the "MAE" measure above each graph). The picture is quite different if we compare the volatility of original (real-time and revised) time series and therefore compare the differences in relative terms. According to noise-to-signal ratios ${ }^{21}$, GDP growth and inflation are subject to similar revisions only in Switzerland. Euro area is the only economy that demonstrates a higher relative amount of data revision in inflation than in GDP growth.

Inspecting the GDP graphs closely reveals some similarities and some specific differences among the featured economies. In most countries, the severity of the economic crisis of 2009 was underestimated, i.e. it appeared milder according to real-time data than it turned out to be after revisions. The economic crisis period also gave rise to the

\footnotetext{
${ }^{21}$ Noise-to-signal ratio is computed as a standard deviation of the revisions divided by the standard deviation of the final value of the variable.
} 
largest revisions on the sample for Czech, Hungarian, and Swiss economies. On the other hand, for example the Polish economy does not display any striking changes in GDP growth during the period of global economic crisis.

The inflation graphs that are depicted in the right-hand panels of Figure 1 do not display many similarities among countries. The most apparent common feature is disinflation in most of the countries during the global economic crisis. Also, the countries of the Visegrád group demonstrate a decline in inflation from values well over $10 \%$ at the beginning of the depicted sample. Further inspection of the regularity of inflation revisions indicates autocorrelation in lag 2 and 4 in some countries. This autocorrelation seems to be an artifact of seasonal adjustment of the underlying CPI series. However, since the series of revisions do not enter the estimation (separate data vintages do), this problem only affects the statistics in Table $2 .^{22}$

Table 2 summarizes the data revision statistics. Revisions are unbiased for all studied countries. Most of the correlations are very high, which means that final and real-time data have very similar dynamics. However, there are a few exceptions with unusually "low" correlation values. The highlighted values in Table 2 point out revisions of GDP growth in Switzerland and Sweden. These correlation coefficients are lower than 0.8 and the corresponding panels in Figure 1 also show only slightly similar dynamics between real-time series and final revised series.

The GDP growth figures in the euro area suffer from frequent underestimation, with the real-time estimate lower than final data $63 \%$ of the time.

The noise-to-signal ratio for GDP growth confirms that the relative magnitude of revisions is lowest for the euro area. The two economies with highest noise-to-signal ratios are the same as the two economies with lowest correlations between real-time and final data. This fact only reasserts the observation of high noise and variability in GDP revisions in Switzerland and Sweden. Noise-to-signal ratios for inflation are usually lower than for GDP growth. The only exception to this is seen in the euro area, with N/S=0.29 for GDP growth and N/S=0.40 for inflation.

Table 2 Summary Statistics of Data Revisions

\begin{tabular}{lcccccccccc} 
& Mean & Min & Max & St. Dev. & RMSE & N/S & Corr & p-val & AR(1) & Rev+ \\
\hline Output growth & & & & & & & & & & \\
Czech Rep. & 0.13 & -6.77 & 3.46 & 1.80 & 1.80 & 0.49 & 0.88 & 0.68 & 0.32 & 0.58 \\
Poland & 0.04 & -5.86 & 7.72 & 2.17 & 2.18 & 0.52 & 0.91 & 0.83 & -0.40 & 0.57 \\
Hungary & -0.19 & -6.14 & 3.63 & 1.73 & 1.74 & 0.49 & 0.88 & 0.49 & 0.36 & 0.40 \\
Switzerland & 0.17 & -8.93 & 2.80 & 1.67 & 1.68 & 0.72 & 0.72 & 0.43 & 0.02 & 0.59 \\
Sweden & 0.33 & -6.07 & 7.59 & 2.54 & 2.56 & 0.67 & 0.73 & 0.14 & -0.11 & 0.52 \\
EA12 & 0.14 & -1.59 & 2.26 & 0.71 & 0.73 & 0.29 & 0.96 & 0.15 & 0.07 & 0.63 \\
\hline
\end{tabular}

\footnotetext{
${ }^{22}$ Also, note that section 3.5 introduced CPI not s.a. as a model variant with CPI that is not seasonally adjusted.
} 


\begin{tabular}{lllllllllll}
\hline Inflation & & & & & & & & & & \\
Czech Rep. & -0.02 & -2.71 & 1.20 & 0.73 & 0.73 & 0.20 & 0.98 & 0.73 & 0.00 & 0.54 \\
Poland & 0.03 & -2.36 & 2.66 & 0.83 & 0.83 & 0.19 & 0.98 & 0.60 & -0.16 & 0.54 \\
Hungary & 0.01 & -2.02 & 2.56 & 0.93 & 0.93 & 0.20 & 0.98 & 0.94 & -0.31 & 0.45 \\
Switzerland & 0.00 & -2.81 & 2.41 & 0.72 & 0.72 & 0.61 & 0.80 & 0.99 & -0.51 & 0.48 \\
Sweden & -0.06 & -1.24 & 1.84 & 0.62 & 0.63 & 0.30 & 0.95 & 0.21 & -0.28 & 0.40 \\
EA12 & 0.04 & -1.86 & 1.54 & 0.44 & 0.45 & 0.40 & 0.91 & 0.29 & -0.14 & 0.59 \\
\hline
\end{tabular}

Notes: N/S denotes noise-to-signal ratio, defined as the standard deviation of the revisions divided by the standard deviation of the final value of the variable; Corr is the correlation of final and real-time data; $p$-val is a p-value for a test that the mean revision is zero using autocorrelation and heteroscedasticity-consistent standard errors. AR(1) denotes an autocorrelation coefficient of the first order (missing data are estimated in an iterative fashion using default order state-space models); Rev+ denotes the frequency at which final data is greater than real-time data, i.e. final revision is positive. Results discussed in the text are highlighted.

Table 3 offers summary statistics for trend revisions. As section 3.2 explained, when new data points become available, they allow for better estimation of the trend. Changes in trend estimates then change the de-trended values that enter the estimation. The characteristics of these changes in de-trended values are exactly what the concept of trend revision aims to capture. Technically, at each point in time, only the latest de-trended value forms the so-called quasi real-time data. The difference between final data and quasi real-time data is then the trend revision.

All trend revisions are highly (first-order) autocorrelated. Over/underestimation of final trend is roughly balanced for all economies except for the euro area, where quasi realtime data overestimate the final trend in $64 \%$ of periods. The $p$-val result for Poland also stands out in Table 3. It is 0.08 , which makes it the only biased trend revision, i.e. the mean of the revision -0.39 is statistically different from zero at the 0.1 significance level.

Table 3 Summary Statistics of Trend Revisions

Mean Min Max St. Dev. RMSE N/S Corr p-val AR(1) Rev+

\begin{tabular}{lllllllllll}
\hline Interest rate & & & & & & & & & & \\
Czech Rep. (HP) & -0.15 & -1.49 & 1.21 & 0.68 & 0.70 & 0.44 & 0.91 & 0.39 & 0.98 & 0.57 \\
Poland (HP) & -0.39 & -2.16 & 0.63 & 0.86 & 0.95 & 0.43 & 0.91 & 0.08 & 0.98 & 0.50 \\
Hungary (HP) & -0.14 & -2.11 & 1.39 & 0.72 & 0.74 & 0.55 & 0.85 & 0.42 & 0.93 & 0.51 \\
Switzerland (HP) & -0.03 & -0.97 & 1.37 & 0.50 & 0.50 & 0.70 & 0.75 & 0.81 & 0.97 & 0.50 \\
Sweden (HP) & 0.01 & -0.95 & 1.58 & 0.51 & 0.51 & 0.63 & 0.79 & 0.97 & 0.95 & 0.41 \\
EA12 (linear) & 0.06 & -0.58 & 1.12 & 0.41 & 0.41 & 0.40 & 0.92 & 0.56 & 0.98 & 0.36 \\
\hline
\end{tabular}

Notes: Corr is the correlation of final and quasi real-time data, Rev+ denotes the frequency at which final data is greater than quasi real-time data. HP denotes the Hodrick-Prescott filter as a detrending method $(\lambda=1600)$, linear denotes linear time trend as a detrending method. For other notes see Table 2. 


\section{Recursive Estimates of Model Parameters}

\section{$5.1 \quad$ Czech Republic}

Figure 2 displays the evolution of recursive, recursive real-time, and recursive quasi real-time estimates for habit $h$, persistence in domestic supply shock $\rho_{a}$, and persistence in the growth rate of world-wide technology shock $\rho_{z}$. Probability bands are drawn around quasi real-time estimates and this depiction is therefore convenient for identifying deviations from quasi real-time estimates.

Starting with the parameter of habit in consumption, the evolution of the estimates is different over time. All real-time, quasi real-time and final recursive estimates of the habit parameter drop during the onset of the economic crisis (2008q4). However, the evolution of the estimates differs in subsequent periods. The parameter estimate drops in $2008 \mathrm{q} 4$ and remains at a lower value according to fully revised data. However, should the researcher use a time series with mixed revised and unrevised data in vintages 2009q1-2010q4, the results would suggest that the value of the habit parameter jumped back to high values immediately after $2008 \mathrm{q} 4$. It can therefore be argued that the use of (a mix of) unrevised data results in a different estimate of habit in consumption. Note that the depicted results are for $Y O Y$ model formulation, which supposes that central authorities react to year-on-year changes. As can be seen in Table 4, the results are not robust to other model specifications.

Another selected example estimated on Czech data is for persistence in domestic supply shock $\rho_{a}$. According to data available in real-time, the evolution of the parameter is almost constant at value 0.95 in the pre-crisis periods, before dropping during 2008 to values close to the prior mean, and remaining there. However, fully revised data suggest that the evolution was in reality not an unexpected drop, but a continuous decline of the parameter. Therefore, if a researcher uses revised data, she would be aware of the decline in the parameter from 2005; but if a researcher uses a mix of unrevised and revised data (downloaded from databases in real-time), the parameter's decline is not apparent until 2008q3. Note that the depicted model version is CPI not s.a., where the price index is not seasonally adjusted. The results are quite robust, since only two of six estimated variants do not demonstrate statistically significant results.

Our third selected example somewhat resembles the first case. The persistence in the growth rate of world-wide technology shock $\rho_{z}$ jumps up in $2008 \mathrm{q} 4$ in all estimations, but its subsequent evolution is different. Real-time (and probably also quasi real-time) data indicate that the parameter values returned to pre-crisis lower levels. However, this observation is illusory as can be seen from the results with fully revised data, which indicate that the value of the parameter remains high as the crisis continues. 
Figure 2 Recursive Estimates of Habit $h$, Persistence in Domestic Supply Shock $\rho_{a}$, and Persistence in the Growth Rate of World-Wide Technology Shock $\rho_{z}$, Czech Economy
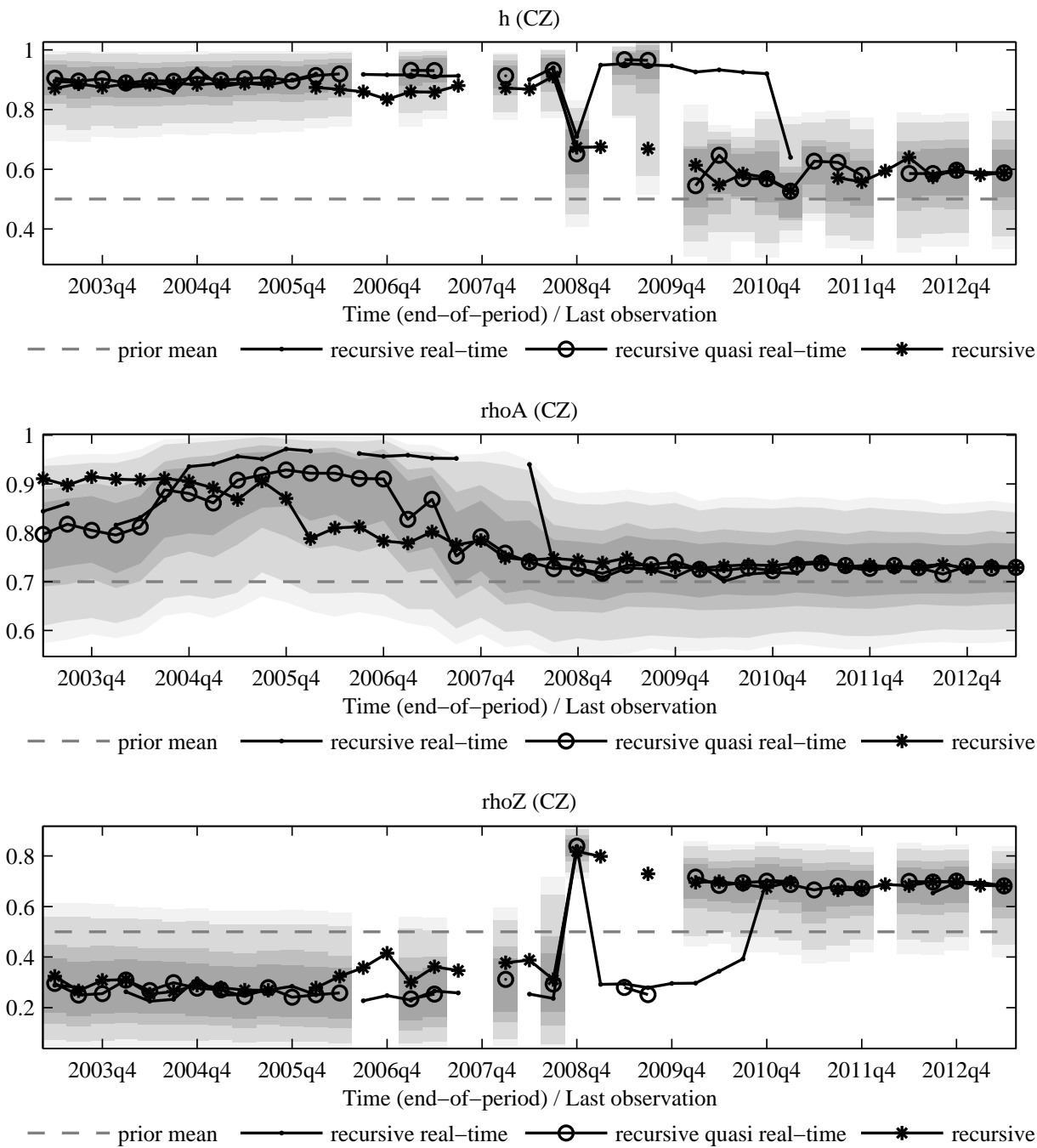

Notes: The depicted estimates are posterior modes with 95\%, 90\%, 68\%, and 50\% Highest Posterior Density Interval (HPDI) for recursive quasi real-time estimates.

Table 4 presents the significance values for various model alternatives in order to determine whether the difference between recursive real-time estimates and the remaining estimates is statistically significant. Please note that, in order to conserve space, results for parameters that do not display a single statistically significant result (at significance level 0.1 or lower) are not reported. 
Table 4 Significance Values for Estimates on Czech and Euro Area Economies

\begin{tabular}{|c|c|c|c|c|c|c|}
\hline & baseline & CPI not s.a. & GDP HP & rolling & YOY & YOY+GDP HP \\
\hline \multicolumn{7}{|c|}{$\tau-$ coefficient of relative risk aversion } \\
\hline Data revision & 0.34 & 0.30 & 0.54 & 0.56 & 0.36 & 0.20 \\
\hline Trend revision & 0.64 & 0.53 & 0.56 & 0.68 & 0.66 & 0.47 \\
\hline Total revision & 0.22 & 0.22 & 0.51 & 0.54 & 0.35 & $0.10^{*}$ \\
\hline \multicolumn{7}{|c|}{$h$ - habit (persistence) in consumption } \\
\hline Data revision & 0.54 & 0.59 & $0.08^{*}$ & 0.25 & $0.01^{* * *}$ & 0.30 \\
\hline Trend revision & 0.62 & 0.55 & 0.14 & 0.40 & $0.01^{* * *}$ & 0.30 \\
\hline Total revision & 0.55 & 0.57 & $0.07^{*}$ & 0.28 & $0.01^{* * *}$ & 0.43 \\
\hline \multicolumn{7}{|c|}{$\rho_{a}-$ AR1 persistence in domestic supply shock } \\
\hline Data revision & 0.18 & $0.07^{*}$ & 0.61 & 0.12 & 0.74 & $0.04^{* *}$ \\
\hline Trend revision & 0.15 & 0.19 & 0.72 & $0.01^{* * *}$ & 0.79 & 0.35 \\
\hline Total revision & $0.02^{\star *}$ & $0.05^{\star *}$ & 0.50 & $0.01^{* * *}$ & 0.71 & $0.01^{* * *}$ \\
\hline \multicolumn{7}{|c|}{$\rho_{z}-$ AR1 persistence in the growth rate of world-wide technology shock } \\
\hline Data revision & 0.55 & 0.67 & $0.06^{*}$ & $0.07^{*}$ & $0.01^{* * *}$ & $0.02^{* *}$ \\
\hline Trend revision & 0.48 & 0.43 & 0.27 & $0.03^{* *}$ & $0.02^{* *}$ & $0.06^{*}$ \\
\hline Total revision & 0.57 & 0.44 & 0.12 & 0.19 & $0.01^{* * *}$ & 0.16 \\
\hline
\end{tabular}

Notes: Numbers shown in the table are the lowest levels of significance at which posterior mode is out of Highest Posterior Density interval bands for the most different estimates. Data revision relates to quasi real-time versus real-time results, Trend revision relates to computation of significance values on recursive versus quasi real-time results, and Total revision relates to recursive versus real-time results. CPI not s.a. stands for the model variant with Consumer Price Index not seasonally adjusted, GDP HP denotes a variant with growth rate of Gross Domestic Product detrended using the Hodrick-Prescott filter, rolling uses an estimation (of baseline model) in a moving window of fixed length 30, YOY stands for a variant with monetary authorities that operate year-on-year (rather than quarter-on-quarter) changes and YOY+GDP HP denotes a variant with monetary authorities that operate year-on-year changes and whose GDP is detrended using the HP filter. Values lower than or equal to 0.1 are denoted with a star, those lower than or equal to 0.05 with two stars, and finally, lower than or equal to 0.01 with three stars (due to computational procedure, values in the table are rounded up). Parameters with no statistically significant results at 0.1 level are not displayed, in order to conserve space.

The individual results in Table 4 were discussed earlier in this paper, therefore here we shall concentrate on the big picture of the results. The results do not seem to demonstrate any particular regularity: statistically significant results can be found in all model variants, and there does not seem to be any pattern in the results, except that baseline and $C P I$ not s.a. are probably less prone to have statistically significant results. On the other hand, rolling, YOY and $Y O Y+G D P H P$ have more statistically significant results. ${ }^{23}$

\footnotetext{
${ }^{23}$ Note that the high number of statistically significant values is also supported by results that are
} 
The most robust result is for persistence in domestic supply shock $\rho_{a}$. The persistence in the shock slowly declined in the period 2004-2008. The illusory results using real-time data suggest there was a steep drop in the parameter in 2008.

\subsection{Hungary}

This subsection investigates the case of small open economy of Hungary in interaction with the euro area. Figure 3 depicts the evolution of intratemporal elasticity of substitution between domestic and imported consumption goods $\eta$, AR 1 persistence in domestic supply shock $\rho_{a}$, and AR1 persistence in domestic demand shock $\rho_{g}$.

All depicted parameter estimates display rather different patterns of evolution when compared with the case of the Czech Republic. All graphs indicate that the evolution of real-time estimates is partially or permanently lower than that of revised estimates. The first graph, showing rolling estimates of intratemporal elasticity of substitution between domestic and imported consumption goods $\eta$ indicates that unrevised data consistently result in a lower value of the parameter than revised data.

The second and the third panel display the persistence of supply and demand shocks. Both persistence trends are fairly constant with revised data, while real-time data indicate (statistically significantly) lower values until 2008.

Figure 3 Recursive Estimates of Intratemporal Elasticity of Substitution between Domestic and Imported Consumption Goods $\eta$, AR1 Persistence in Domestic Supply Shock $\rho_{a}$, and AR1 Persistence in Domestic Demand Shock $\rho_{g}$, Hungarian Economy

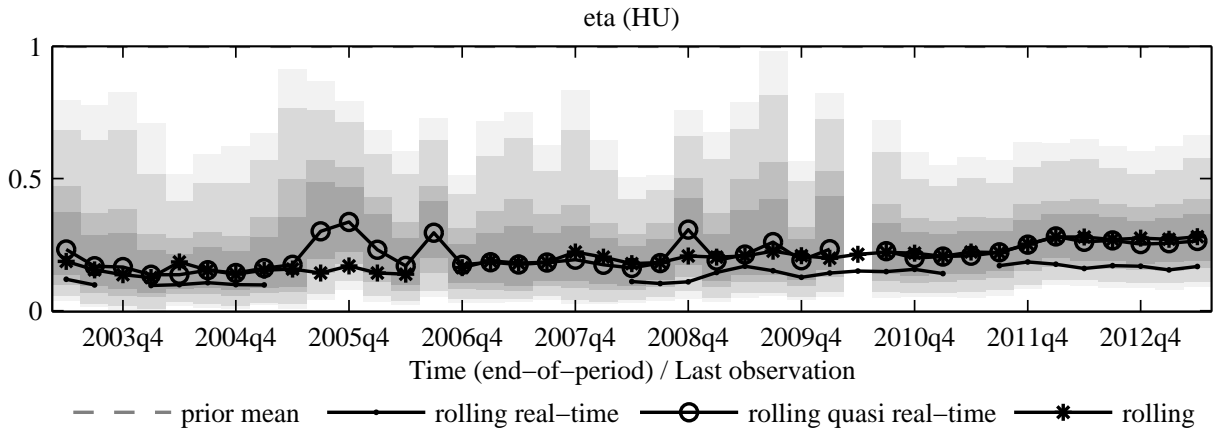

due to the multimodality of the posterior distributions in question. 


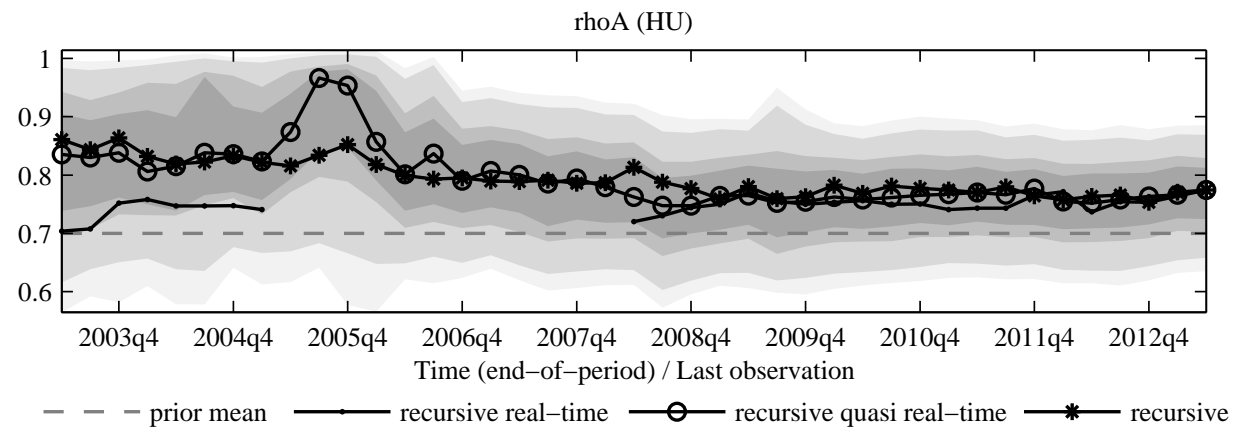

rhoG $(\mathrm{HU})$

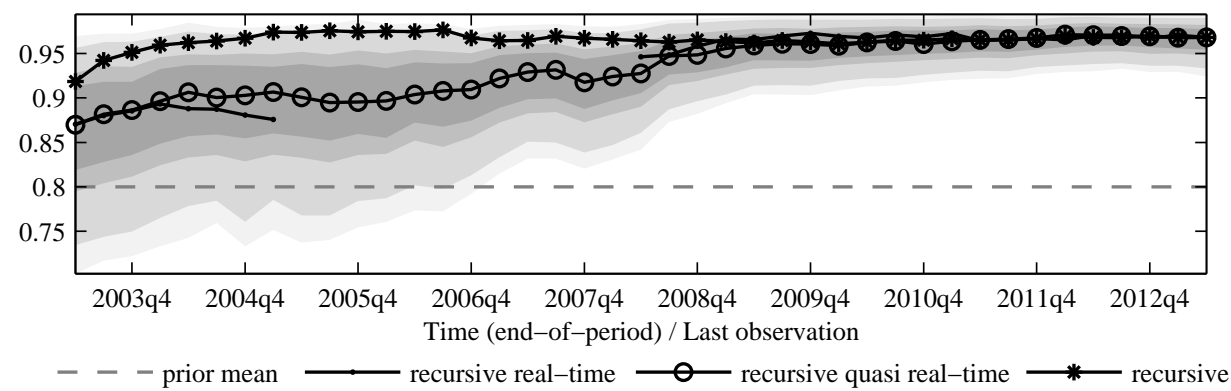

Notes: The depicted estimates are posterior modes with 95\%, 90\%, 68\%, and 50\% Highest Posterior Density Interval (HPDI) for recursive quasi real-time estimates.

Table 5 shows parameters for Hungarian economy that demonstrate at least one statistically significant result. However, the robustness of these results is mostly weak. Reasonably robust results are only found for persistence of demand and of world-wide technology shocks. The result for the demand shock was discussed earlier in this paper; the results for the persistence in the growth rate of world-wide technology shock are probably due to shifting between regimes. ${ }^{24}$

Table 5 Significance Values for Estimates on Hungarian and Euro Area Economies

\begin{tabular}{|c|c|c|c|c|c|c|}
\hline & baseline & CPI not s.a. & GDP HP & rolling & YOY & YOY+GDP HP \\
\hline \multicolumn{7}{|c|}{$h$ - habit (persistence) in consumption } \\
\hline Data revision & 0.52 & 0.66 & 0.64 & 0.45 & $0.01^{* * *}$ & 0.12 \\
\hline Trend revision & 0.37 & 0.42 & 0.43 & 0.43 & 0.54 & $0.01^{* * *}$ \\
\hline Total revision & 0.26 & 0.49 & 0.53 & 0.35 & 0.20 & 0.43 \\
\hline
\end{tabular}

\footnotetext{
${ }^{24}$ Note that all reported results (including this one) successfully passed the Gelman and Rubin (1992) convergence check, see subsection 3.3 for details of the estimation.
} 


\begin{tabular}{|c|c|c|c|c|c|c|}
\hline \multicolumn{7}{|c|}{$\alpha$-import share } \\
\hline Data revision & 0.57 & 0.41 & 0.54 & $0.04^{* *}$ & $0.01^{* * *}$ & 0.50 \\
\hline Trend revision & 0.69 & 0.64 & 0.54 & 0.34 & 0.16 & 0.74 \\
\hline Total revision & 0.61 & 0.60 & 0.30 & 0.39 & 0.19 & 0.46 \\
\hline \multicolumn{7}{|c|}{$\eta$ - intratemporal elasticity of substitution between domestic and imported consumption goods } \\
\hline Data revision & 0.16 & 0.48 & 0.44 & $0.08^{*}$ & $0.01^{* * *}$ & $0.03^{* *}$ \\
\hline Trend revision & 0.45 & 0.76 & 0.74 & 0.23 & 0.12 & 0.12 \\
\hline Total revision & 0.39 & 0.51 & 0.52 & 0.26 & $0.04^{\star *}$ & 0.20 \\
\hline \multicolumn{7}{|c|}{$\rho_{a}-\mathrm{AR} 1$ persistence in domestic supply shock } \\
\hline Data revision & 0.15 & 0.68 & 0.52 & $0.05^{\star *}$ & 0.51 & 0.36 \\
\hline Trend revision & $0.03^{* *}$ & 0.20 & 0.52 & $0.03^{* *}$ & 0.22 & 0.33 \\
\hline Total revision & $0.08^{*}$ & 0.16 & 0.34 & $0.07^{*}$ & 0.49 & $0.09^{*}$ \\
\hline \multicolumn{7}{|c|}{$\rho_{g}-\mathrm{AR} 1$ persistence in domestic demand shock } \\
\hline Data revision & 0.49 & 0.34 & 0.46 & 0.25 & 0.53 & 0.49 \\
\hline Trend revision & $0.02^{\star *}$ & $0.02^{* *}$ & 0.51 & $0.01^{* \star *}$ & 0.42 & $0.06^{*}$ \\
\hline Total revision & $0.01^{* * *}$ & $0.01^{* * *}$ & 0.52 & $0.01^{* * *}$ & 0.79 & $0.08^{*}$ \\
\hline \multicolumn{7}{|c|}{$\rho_{z}-$ AR1 persistence in the growth rate of world-wide technology shock } \\
\hline Data revision & 0.42 & 0.65 & 0.73 & $0.01^{* * *}$ & $0.01^{* * *}$ & 0.54 \\
\hline Trend revision & $0.04^{* *}$ & 0.32 & $0.01^{* * *}$ & $0.01^{* * *}$ & $0.01^{* * *}$ & 0.26 \\
\hline Total revision & $0.02^{* *}$ & 0.38 & $0.01^{* * *}$ & $0.01^{* * *}$ & $0.03^{* *}$ & 0.17 \\
\hline
\end{tabular}

See notes to Table 4.

\subsection{Poland}

This section presents the results for a model on the domestic economy of Poland. No results are depicted for Poland, since there are no robust statistically significant results (see also Table 6).

This result may seem puzzling since the descriptive statistics of data revisions in Table 2 are similar to the equivalent Czech and Hungarian statistics, and the statistics of trend revisions in Table 3 display the only biased trend revision in the whole study. Yet, despite this, there seem to be only minor differences between estimations with fully revised data and those using real-time data for Poland. This observation underlines the importance of further analysis, such as the analysis in this paper. Since the consequences of data and trend revisions for model estimation do not seem to be trivial, one cannot conjecture the consequences of quality of data for model results. 
Table 6 Significance Values for Estimates on Polish and Euro Area Economies

\begin{tabular}{|c|c|c|c|c|c|c|}
\hline & baseline & CPI not s.a. & GDP HP & rolling & YOY & YOY+GDP HP \\
\hline \multicolumn{7}{|c|}{$h$ - habit (persistence) in consumption } \\
\hline Data revision & 0.37 & 0.45 & 0.74 & 0.13 & 0.38 & $0.07^{*}$ \\
\hline Trend revision & 0.40 & 0.48 & 0.74 & 0.63 & 0.52 & 0.17 \\
\hline Total revision & 0.31 & 0.33 & 0.66 & 0.27 & 0.46 & 0.11 \\
\hline \multicolumn{7}{|c|}{$\alpha$-import share } \\
\hline Data revision & 0.41 & 0.66 & 0.20 & 0.11 & $0.08^{*}$ & $0.04^{* *}$ \\
\hline Trend revision & 0.72 & 0.77 & 0.75 & 0.42 & 0.31 & 0.13 \\
\hline Total revision & 0.42 & 0.57 & 0.21 & 0.15 & $0.10^{*}$ & 0.12 \\
\hline
\end{tabular}

$\eta$ - intratemporal elasticity of substitution between domestic and imported consumption goods

\begin{tabular}{|c|c|c|c|c|c|c|}
\hline Data revision & 0.38 & 0.26 & 0.24 & $0.09^{*}$ & 0.41 & 0.15 \\
\hline Trend revision & 0.71 & 0.75 & 0.83 & $0.05^{* *}$ & 0.45 & 0.33 \\
\hline Total revision & 0.31 & 0.17 & 0.25 & $0.10^{*}$ & 0.24 & $0.06^{*}$ \\
\hline \multicolumn{7}{|c|}{$\rho_{a}-\mathrm{AR} 1$ persistence in domestic supply shock } \\
\hline Data revision & 0.58 & 0.65 & 0.74 & 0.43 & 0.31 & 0.44 \\
\hline Trend revision & 0.65 & 0.60 & 0.64 & 0.11 & 0.62 & 0.61 \\
\hline Total revision & 0.52 & 0.69 & 0.66 & $0.06^{*}$ & 0.29 & 0.43 \\
\hline \multicolumn{7}{|c|}{$\rho_{g}-$ AR1 persistence in domestic demand shock } \\
\hline Data revision & 0.23 & 0.16 & 0.25 & 0.28 & 0.20 & 0.15 \\
\hline Trend revision & 0.23 & 0.18 & 0.68 & 0.33 & 0.59 & 0.17 \\
\hline Total revision & 0.14 & 0.12 & 0.27 & $0.10^{*}$ & 0.21 & 0.25 \\
\hline \multicolumn{7}{|c|}{$\rho_{z}-$ AR1 persistence in the growth rate of world-wide technology shock } \\
\hline Data revision & 0.22 & 0.55 & 0.68 & 0.15 & 0.56 & $0.01^{* * *}$ \\
\hline Trend revision & 0.17 & 0.30 & 0.70 & 0.58 & 0.60 & $0.01^{* * *}$ \\
\hline Total revision & 0.33 & 0.27 & 0.64 & 0.34 & 0.47 & $0.01^{* * *}$ \\
\hline
\end{tabular}

See notes to Table 4.

\subsection{Switzerland}

The quality of Swiss data is quite good (see section 4) and this fact is also reflected in the relatively low number of statistically significant results in Table 7 . The result depicted in Figure 4 is the evolution of the persistence in domestic supply shock $\rho_{g}$. Recursive real-time and recursive quasi real-time estimates are consistently lower than recursive estimates for the time period prior to 2009. This observation suggests that revision as late as 2009 unveiled the "true" value of the parameter during the period 2003-2008. 
Figure 4 Recursive Estimates of Persistence in Domestic Supply Shock $\rho_{g}$, Swiss Economy

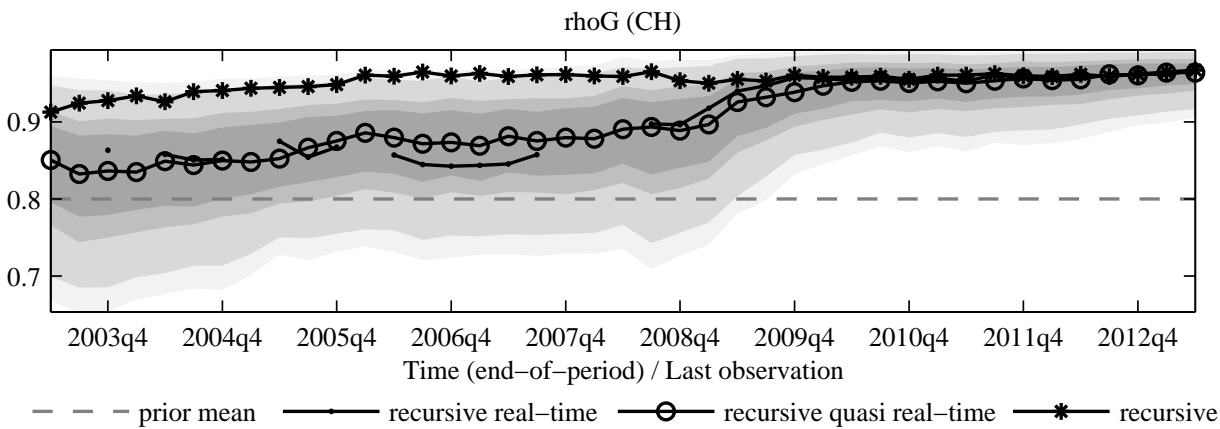

Table 7 Significance Values for Estimates on Swiss and Euro Area Economies

\begin{tabular}{|c|c|c|c|c|c|c|}
\hline \multicolumn{7}{|c|}{$h$ - habit (persistence) in consumption } \\
\hline Data revision & 0.59 & 0.68 & $0.01^{* * *}$ & 0.48 & 0.48 & 0.64 \\
\hline Trend revision & 0.79 & 0.68 & 0.62 & 0.68 & 0.57 & 0.66 \\
\hline Total revision & 0.75 & 0.75 & 0.12 & 0.58 & 0.60 & 0.75 \\
\hline \multicolumn{7}{|c|}{$\rho_{g}-$ AR1 persistence in domestic demand shock } \\
\hline Data revision & 0.50 & 0.56 & 0.49 & 0.47 & 0.43 & 0.48 \\
\hline Trend revision & $0.06^{*}$ & $0.06^{*}$ & 0.76 & 0.13 & 0.69 & $0.06^{*}$ \\
\hline Total revision & $0.03^{* *}$ & $0.03^{* *}$ & 0.55 & 0.18 & 0.41 & $0.02^{* *}$ \\
\hline \multicolumn{7}{|c|}{$\rho_{z}-$ AR1 persistence in the growth rate of world-wide technology shock } \\
\hline Data revision & 0.47 & 0.36 & 0.55 & 0.22 & $0.04^{* *}$ & $0.05^{\star *}$ \\
\hline Trend revision & 0.40 & $0.02^{* *}$ & 0.23 & 0.57 & $0.06^{*}$ & 0.17 \\
\hline Total revision & 0.27 & $0.03^{* *}$ & 0.41 & 0.29 & $0.01^{* \star *}$ & $0.02^{* *}$ \\
\hline
\end{tabular}

See notes to Table 4.

\subsection{Sweden}

The results for the Swedish economy are almost exclusively driven by the bimodality of posterior distributions and switching between the modes. ${ }^{25}$ As a result, no graphical figure is presented here, and the number of statistically significant results in Table 8 is hardly comparable to the results in other countries.

\footnotetext{
${ }^{25}$ Again, please note that all results passed the convergence diagnostics checks described in subsection 3.3.
} 
Table 8 Significance Values for Estimates on Swedish and Euro Area Economies

\begin{tabular}{|c|c|c|c|c|c|c|}
\hline & baseline & CPI not s.a. & GDP HP & rolling & YOY & YOY+GDP HP \\
\hline \multicolumn{7}{|c|}{$\theta_{H}-$ fraction of domestic producers who do not change prices } \\
\hline Data revision & $0.08^{*}$ & $0.07^{*}$ & 0.44 & 0.32 & 0.18 & 0.69 \\
\hline Trend revision & 0.49 & 0.70 & 0.69 & 0.81 & 0.55 & 0.75 \\
\hline Total revision & 0.24 & 0.11 & 0.27 & 0.46 & 0.19 & 0.84 \\
\hline \multicolumn{7}{|c|}{$h$ - habit (persistence) in consumption } \\
\hline Data revision & $0.04^{* *}$ & 0.64 & 0.44 & 0.63 & $0.01^{* * *}$ & 0.57 \\
\hline Trend revision & $0.03^{* *}$ & 0.46 & $0.01^{* * *}$ & 0.76 & 0.31 & 0.50 \\
\hline Total revision & 0.42 & 0.64 & 0.47 & 0.47 & $0.01^{* * *}$ & 0.54 \\
\hline \multicolumn{7}{|c|}{$\alpha$-import share } \\
\hline Data revision & $0.01^{* * *}$ & $0.01^{* * *}$ & 0.23 & 0.60 & $0.05^{\star *}$ & 0.63 \\
\hline Trend revision & 0.17 & 0.60 & 0.40 & 0.55 & 0.12 & 0.54 \\
\hline Total revision & $0.09^{*}$ & $0.04^{* *}$ & 0.24 & $0.09^{*}$ & $0.04^{* *}$ & 0.39 \\
\hline \multicolumn{7}{|c|}{$\eta$ - intratemporal elasticity of substitution between domestic and imported consumption goods } \\
\hline Data revision & $0.01^{* * *}$ & $0.01^{* * *}$ & $0.02^{* *}$ & 0.29 & $0.04^{* *}$ & 0.27 \\
\hline Trend revision & 0.17 & 0.14 & 0.70 & 0.64 & 0.15 & 0.28 \\
\hline Total revision & $0.01^{* * *}$ & $0.01^{* * *}$ & $0.01^{* * *}$ & 0.14 & $0.01^{* * *}$ & 0.17 \\
\hline \multicolumn{7}{|c|}{$\rho_{z}-\mathrm{AR} 1$ persistence in the growth rate of world-wide technology shock } \\
\hline Data revision & $0.01^{* * *}$ & $0.01^{* * *}$ & 0.61 & 0.21 & $0.01^{* * *}$ & 0.58 \\
\hline Trend revision & 0.35 & 0.31 & $0.05^{\star *}$ & 0.51 & 0.13 & 0.16 \\
\hline Total revision & $0.01^{* \star *}$ & $0.06^{*}$ & 0.68 & $0.01^{* * *}$ & $0.01^{* * *}$ & 0.22 \\
\hline
\end{tabular}

See notes to Table 4.

\subsection{Impulse Response Functions Analysis}

This section addresses the question as to whether the differences in the parameter estimates based on real-time and revised data are also associated with different model behavior. Since the number of impulse response functions (IRFs) is very large, ${ }^{26}$ Figure 5 only depicts selected impulse response functions in order to illustrate the possibilities for different model behavior if the model is estimated on real-time and revised data. Note that the depicted IRFs are computed from posterior medians and are therefore not sensitive to convergence/bimodality issues.

\footnotetext{
${ }^{26}$ For each country, 232 responses can be measured, for each of 6 variants and up to 41 recursive estimates. This results in up to $232 \cdot 6 \cdot 41=57072$ impulse response functions for each country.
} 


\section{Figure 5 Selected Impulse Response Functions}

SE, YOY, 2006q4, gdp growth (demand shock)

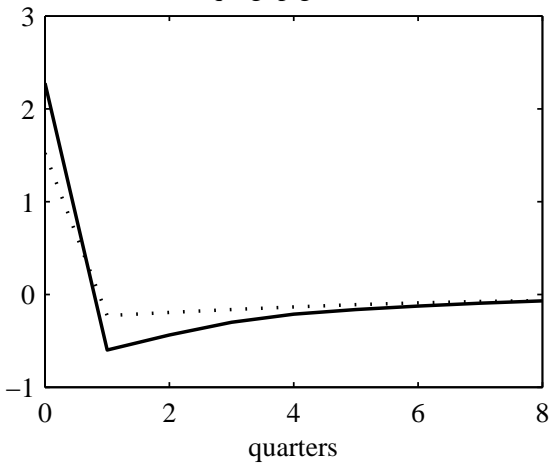

CZ, baseline, 2006q3, int. rate (supply shock)

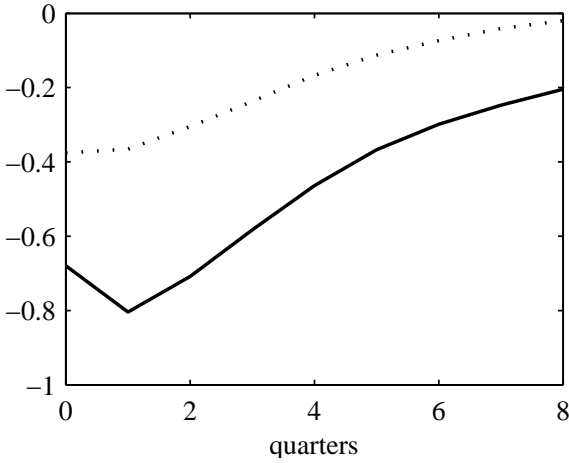

CH, gdp HP, 2008q3, gdp growth (WWtech shock)

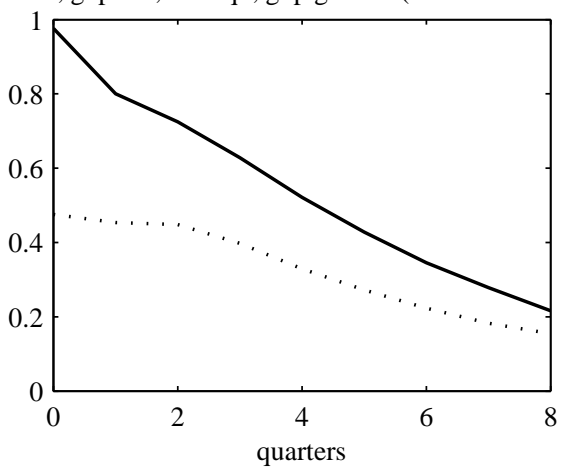

SE, YOY+gdp HP, 2005q3, inflation (WWtech shock)

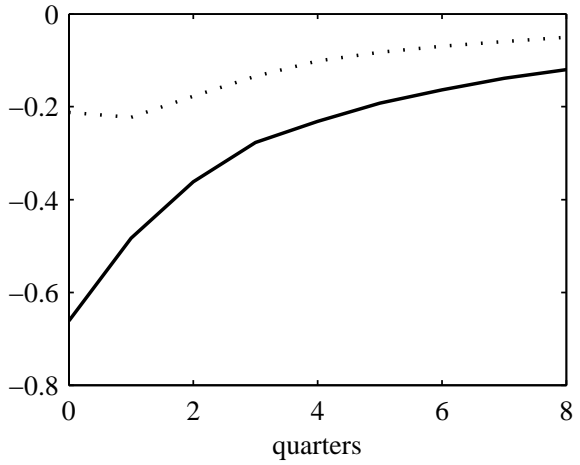

PL, gdp HP, 2005q4, inflation (WWtech shock)

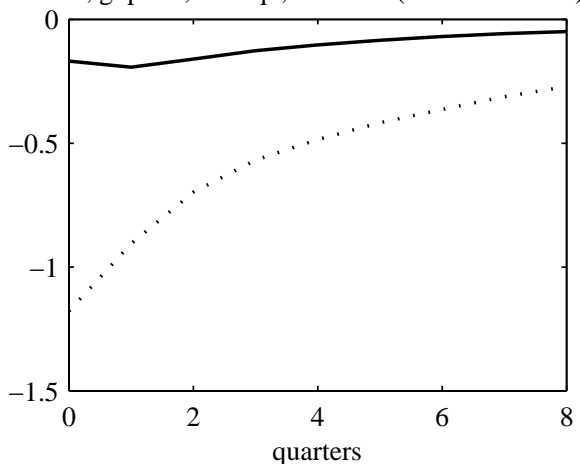

HU, YOY+gdp HP, 2009q2, inflation (WWtech shock)

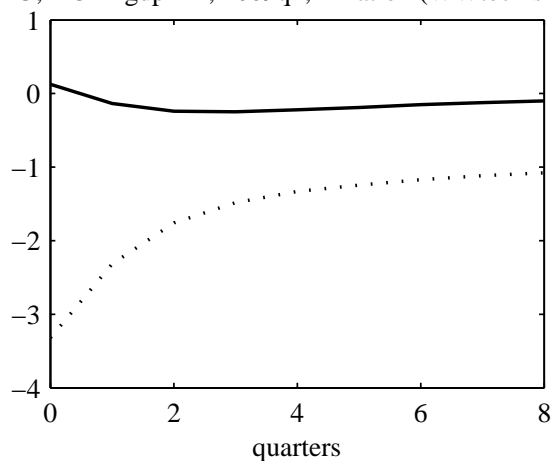

Notes: The first two letters are the country abbreviations (see notes to Figure 1), the information given second in the title is the model variant (see subsection 3.4), the following code identifies the last observation of the recursive estimate used, and the last part of the title refers to the response being drawn: the response of the observable variable referred to is drawn in the figure, and the shock identified is stated in the parentheses (WWtech shock denotes the world-wide technology shock). All shocks are positive (in these cases, also favorable) and in the magnitude of standard deviations of the innovation in question. The dotted line corresponds to real-time data results, solid lines show fully revised results. 
The first panel of Figure 5 depicts the IRFs for the Swedish small open economy. The $Y O Y$ formulation indicates that monetary rules are in year-on-year formulation. The responses being drawn are from recursive estimates with their last observation in the fourth quarter of 2006. The shock is a demand (or market-clearing) shock and we observe the GDP growth reaction in the domestic (Swedish) economy. The response is qualitatively similar when we compare the IRF based on real-time and revised data, but quantitatively milder when considering real-time data. The impact response is only $1.5 \%$ when real-time data are considered, but in reality it is $2.3 \%$. Considering the importance of this result for monetary policy, negative instead of positive demand shock may more suitable. In such case, real-time results underestimate the drop in output growth by 0.8 of a percentage point.

The third panel depicts the domestic interest rate response to favorable supply shock in the Czech small open economy (SOE) model. The response based on real-time data is milder and also does not predict the trough in the IRF found in the first quarter after the shock. Therefore, in this case, there is a quantitative difference between the two data types, and also a slightly different IRF evolution. Again, this result may be more interesting from the point of view of policy institutions if we flip over the graph and suppose an unfavorable supply shock. In such a case, real-time data would suggest only half of the rise in the monetary instrument really required to counter the inflationary pressures.

The fifth panel of Figure 5 depicts the results for the Swiss SOE model. Most of the major differences in IRFs for Switzerland are similar. Typically, the real-time data underestimate the impact of the shock on the domestic (and also foreign) GDP growth rate. However, unlike in the first panel, where we observed a GDP growth reaction in Sweden, here the difference is not just in the impact, but the convergence towards the steady state is also different. The reason for this is mainly that the shock is to the growth rate of the world-wide technology shock, which influences the balanced growth path.

The graphs on which we have commented show the results of various shocks (supply, demand, and world-wide technology), in various economies (Swedish, Czech, and Swiss), and with various observable variables (GDP growth, interest rate). This selection suggests that different shapes and/or magnitudes of IRFs may be observed in various model settings, when using real-time data as opposed to revised data.

The right-hand panels of Figure 5 depict inflation reactions to a favorable world-wide technology shock. Panels 2 and 4 (for the Swedish and Polish economies, respectively) look alike, except the lines are swapped. This suggests that real-time data may suggest not only a stronger reaction than final data, but in some cases also a weaker reaction. The last panel shows inflation reaction for the Hungarian SOE. The estimated model for the Hungarian small open economy features some regime switches and jumps of parameters, as already discussed. Several IRFs follow this pattern and are very different, possibly due to regime switches in parameters. The example shows a much more severe reaction of inflation to the world-wide technology shock when calculating based on real-time data. 


\section{Conclusion}

This paper investigates several characteristics of real-time macroeconomic data in Czech, Polish, Hungarian, Swiss, and Swedish economies, and the euro area.

Data revisions of GDP growth and inflation are unbiased and not autocorrelated in all countries. Inflation is usually accurately measured in real-time. The Czech, Polish, and Hungarian economies demonstrate the lowest noise-to-signal ratios (around 0.2). On the other hand, Switzerland has noise-to-signal ratios of above 0.6. GDP growth is generally subject to greater data revision, with noise-to-signal ratios ranging from below 0.3 in the euro area to above 0.7 in the worst cases (Switzerland).

Trend revisions are calculated with linear time trend in the euro area and using the Hodrick-Prescott filter in the remaining economies. As can be expected, trend revisions are highly autocorrelated and unbiased; the only exception is the Polish economy, for which trend revision is biased. Noise-to-signal ratios range from 0.40 in the euro area to 0.70 in Switzerland.

This paper reports many statistically significant differences between parameter estimates based on real-time data and those based on and revised data. These differences can be interpreted as indicating that if a researcher bases her estimates on fully revised data, she will come to different conclusions than she would have if she had used time series downloaded from internet databases, which mix together revised and unrevised data. Economically interesting results were found in several areas.

Some results occurred for parameters that shifted values during the observed time period, which creates a nice natural experiment for testing estimation power with real-time data. In many cases, estimates based on real-time data reacted to economic changes late, or did not react at all. Examples discussed in this paper included, for example, the habit parameter and persistence of supply shock in the Czech economy.

Another group of significant results arose from the long-term over/underestimation of the "true" value of the parameter. In the Hungarian economy, for instance, at least three parameters were found to be underestimated when real-time data were used in the analysis.

Many other results occur due to unsynchronized changes in parameter regimes. This is usually indicated by the skewness or even bimodality of the posterior parameter distribution. Quarter-by-quarter, the information in the data changes, and different modes of the bimodal distribution may become major. Switching between the modes results in apparent sharp changes in the parameter values. If the switches between the use of realtime data and revised data are not synchronized, this results in statistically significant differences between the parameter estimates. The Swedish economy demonstrates many results of this type.

Exemplary impulse response functions suggest that the behavior of the model estimated with real-time data and that estimated with revised data may be very different. There are differences in the impact of the shock as well as the convergence to the steady state. In many cases, the differences between impulse response functions based on real-time data and those based on revised data are economically significant. 
All in all, it is clear that there are consistent differences between parameter estimates calculated using real-time data, and those using revised data. Impulse response analysis suggests that the reactions of the model economy are different and large enough to be policy-relevant. In the context of the analyses conducted in this paper, real-time data matter.

\section{References}

ARUOBA, S. B. (2008): Data Revisions Are Not Well Behaved, Journal of Money, Credit and Banking, 40, 319-340

AURELIO, M. M. (2005): Do we really know how inflation targeters set interest rates? FRB Kansas City Work. Pap. No. 05-02

BELKE, A.; KLOSE, J. (2011): Does the ECB Rely on a Taylor Rule During the Financial Crisis? Comparing Ex-post and Real Time Data with Real Time Forecasts. Economic Analysis \& Policy, 41:147-172.

ČAPEK, J. (2014): Historical Analysis of Monetary Policy Reaction Functions: Do Real-Time Data Matter? Czech Journal of Economics and Finance (Finance a uver), Charles University Prague, Faculty of Social Sciences, vol. 64(6), pages 457-475, December.

CASARES, M.; VÁZQUEZ, J. (2012): Data Revisions in the Estimation of DSGE models. DFAEII 2012.06

CLEMENTS, M.; GALVÃO, A. (2011) Improving real-time estimates of output gaps and inflation trends with multiple-vintage VAR models. Working paper

CROUSHORE, D. (2011): Frontiers of Real-Time Data Analysis, Journal of Economic Literature, 49, 72-100

CROUSHORE, D.; Stark, T. (2003): A real-time data set for macroeconomists: Does the data vintage matter? Review of Economics and Statistics, 85:605-617.

CUSINATO, R.; MINELLA, A.; DA SILVA PÔRTO JÚNIOR, S. (2013): Output gap in Brazil: A real-time data analysis, Empirical Economics, 44, 1113-1127

GALVÃO, A. (2013): Forecasting with DSGE models in the Presence of Data Revisions. 1-23. Working paper

GELMAN, A.; RUBIN, D. B. (1992): Inference from Iterative Simulation Using Multiple Sequences, Statistical Science, Vol. 7, No. 4 (Nov., 1992), pp. 457-472

GERBERDING, C.; SEITZ, F.; WORMS, A. (2005): How the Bundesbank really conducted monetary policy. North American Journal of Economics and Finance, 16:277292. doi: 10.1016/j.najef.2005.05.003

GERDESMEIER, D.; ROFFIA, B. (2005): The relevance of real-time data in estimating reaction functions for the euro area. North American Journal of Economics and Finance. Volume: 16, Issue: 3, Pages: 293-307 
HORVÁTH, R. (2009): The time-varying policy neutral rate in real-time: A predictor for future inflation? Economic Modelling, 26:71-81. doi: 10.1016/j.econmod.2008.05.005

INCE, O.; PAPELL, D. (2013): The (un)reliability of real-time output gap estimates with revised data, Economic Modelling, 33, 713-721

KOLASA, M.; RUBASZEK, M.; SKRZYPCZYŃSKI, P. (2012): Putting the New Keynesian DSGE Model to the Real-Time Forecasting Test. Journal of Money, Credit and Banking 44:1301-1324. doi: 10.1111/j.1538-4616.2012.00533.x

LUBIK, T.; SCHORFHEIDE, F. (2006): A Bayesian Look at the New Open Economy Macroeconomics, NBER Macroeconomics Annual 2005, Volume 20, National Bureau of Economic Research, Inc, 313-382

NERI, S.; ROPELE, T. (2012): Imperfect Information, Real-Time Data and Monetary Policy in the Euro Area. The Economic Journal, Volume 122, Issue 561, pages 651-674

ORPHANIDES, A.; VAN NORDEN, S. (2002): The Unreliability of Output-Gap Estimates in Real Time, The Review of Economics and Statistics, 84, 569-583

ORPHANIDES, A. (2001): Monetary Policy Rules Based on Real-Time Data, The American Economic Review, American Economic Association, 91, pp. 964-985

RUSNÁK, M. (2013): Revisions to the Czech National Accounts: Properties and Predictability, Czech Journal of Economics and Finance, 63, 244-261

VÁZQUEZ, J.; MARÍA-DOLORES, R.; LONDOÑO, J. (2010) Data Revisions and the Monetary Policy Rule: An analysis based on an extension of the basic New Keynesian model. The University of the Basque Country, Mimeo. 